\title{
THE PREVALENCE AND RISK FACTORS OF MUSCULOSKELETAL DISORDERS IN THE HANDS OF FISHERMEN WORKING AS OYSTER SHUCKERS
}

\author{
JIN SUNG PARK ${ }^{1}$, JUN-IL YOO ${ }^{2}$, JAE-BUM NA ${ }^{3}$, and HAN SOO SONG ${ }^{4}$ \\ ${ }^{1}$ Gyeongsang National University School of Medicine and Gyeongsang National University Hospital, \\ Jinju, Republic of Korea \\ Institute of Health Sciences, Department of Orthopaedic Surgery \\ ${ }^{2}$ Gyeongsang National University Hospital, Jinju, Republic of Korea \\ Department of Orthopaedic Surgery \\ ${ }^{3}$ Gyeongsang National University School of Medicine and Gyeongsang National University Hospital, \\ Jinju, Republic of Korea \\ Institute of Health Sciences, Department of Radiology \\ ${ }^{4}$ Chosun University Hospital, Gwang-ju, Republic of Korea \\ Department of Occupational and Environmental Medicine
}

\begin{abstract}
Objectives: This study aimed to investigate the prevalence of musculoskeletal disorders in the hands and wrists of fishermen working as oyster shuckers, and to identify the risk factors associated with oyster shucking. Material and Methods: A total of 590 fishery workers including those working as oyster shuckers in 2015-2017 were included in the study analysis. Hand osteoarthritis (OA), carpal tunnel syndrome (CTS), and ulnar impaction syndrome were diagnosed using X-ray, magnetic resonance imaging, and physical examinations according to each diagnostic criterion. The Rapid Entire Body Assessment was used as a measurement tool for analyzing the occupation-related burden factors. Results: The prevalence of hand OA, CTS, and ulnar impaction syndrome was higher in oyster shuckers than in aquaculture/offshore fishery workers. The prevalence of upper limb disease was higher in oyster shuckers than in other fishery workers, even in the prevalence of exposure to occupational burden factors. In oyster shuckers, the incidence of hand and wrist OA was $84 \%$, that of CTS was $72 \%$, and that of ulnar impaction syndrome was $41 \%$. In addition, oyster shuckers were more likely to be exposed to occupational burden factors than were other types of fishermen. Conclusions: The prevalence of hand OA, CTS, and ulnar impaction syndrome was higher in oyster shuckers. Therefore, proper stretching or exercises for rest and musculoskeletal relaxation, along with health-care education and promotion, will be needed for the fishermen's repeated posture and impact work. Int J Occup Med Environ Health. 2021;34(5):603-15
\end{abstract}

Key words:

osteoarthritis, fishermen, musculoskeletal disorders, wrist, hands, oyster shuckers

Funding: this work was supported from the fund of the research promotion program, Gyeongsang National University, 2016.

Received: October 12, 2020. Accepted: January 4, 2021.

Corresponding author: Jun-Il Yoo, Gyeongsang National University Hospital, Department of Orthopaedic Surgery, 90 Chilamdong, Jinju, Gyeongnamdo 660-702, Republic of Korea (e-mail: furim@daum.net). 


\section{INTRODUCTION}

Oyster farming is one of the major aquaculture fisheries in the south coast of Korea, especially in Tongyeong, and it forms an important part of the local economy. In addition, Korea is one of the world's leading producers of oysters, producing 300000 tons of oysters and 40000 tons of oysters without shells each year [1] (Figure 1). Therefore, oyster shucking, which involves removing oyster shells during oyster harvesting, is an important fishing occupation, with 22000 employees and a relatively high annual profit of over 20 million per person [1]. Given the nature of oyster shucking, however, repeated and persistent hand and wrist burdens are given in a long and constant position, and the proportion of women is too high, resulting in the musculoskeletal disorders of the hand and wrist. However, few studies have been reported [2]. In addition, working in an unnatural position for an extended period of time can place strain on the workers' hips or shoulder joints.

Hsu et al. [2] reported that Taiwanese oyster shuckers' work caused discomfort or pain in the order of prevalence of the back, hand, wrist, shoulder, and elbow joints. However, there have been no reports on the analysis of various musculoskeletal disorders in the hands and wrists, or studies of the relationship between musculoskeletal disorders and oyster shucking.

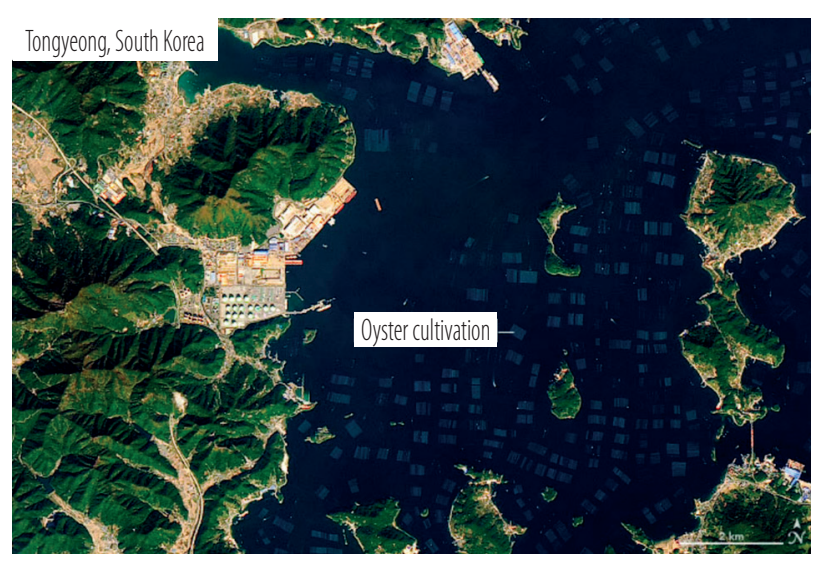

Figure 1. An aerial photo of the Tongyeong's Oyster Farm, Republic of Korea
Therefore, the purpose of this study was to investigate the prevalence of musculoskeletal disorders in the hands and wrists of fishermen working as oyster shuckers, and to identify risk factors associated with oyster shucking.

\section{MATERIAL AND METHODS}

\section{Participants}

In the period of October 2015-August 2017, the subjects visited Gyeongsang National University Hospital in person to receive a survey and a detailed examination.

In 2015, the criteria for selecting the subjects were to have 190 participants who were working as oyster strippers in the Hadong area. The selection criteria for 2016 were to have 250 fishermen who worked in aquaculture or as offshore fishery workers living in Hadong, Sacheon, and Gimhae. The criteria for selection in 2017 were to establish the fishermen's control groups in 2015 and 2016, and targeted 150 office workers who had lived in Gyeongnam for $>10$ years. Finally, a total of 590 subjects from 2015-2017 were included in the study analysis.

\section{Health examination survey}

The one-on-one survey was conducted by nurses who were informed on the objective of this study and who were trained in data collection procedures. The survey included information on socio-demographic variables (age, gender, education, type of fishery, fishery period).

\section{Diagnosis of hand osteoarthritis}

The inclusion criteria for the diagnosis of hand and wrist osteoarthritis (OA) were:

- pain or tenderness of the finger joint and thumb basal joints;

- the radiologic presence of joint space narrowing, subchondral sclerosis, and marked osteophytes;

- the presence of Heberden's node or Bouchard's node, or deformity of the finger joint;

- a loss of the range of motion of fingers joints. 
The exclusion criteria of hand OA were:

- a history of inflammatory arthritis such as rheumatoid arthritis;

- any abnormal findings, such as an old fracture or previous surgery, in radiographs [3].

\section{Diagnosis of carpal tunnel syndrome}

The inclusion criteria for the diagnosis of carpal tunnel syndrome (CTS) were:

- symptoms including sensory abnormalities or pain in the median nerve region, radiating pain in the proximal wrist, night cry or thenar atrophy;

- positive findings of a provocation test, such as Phalen's test, Tinel's sign, and a direct compression test. When both the symptoms and the physical examination showed positive results, the case where the final confirmation was done by an electromyography test was defined as CTS.

The exclusion criteria were:

- a history of previous surgery around the wrist;

- negative finding of an electromyography test, even if the patients had the symptoms or physical examination suggesting CTS [4].

\section{Diagnosis of ulnar impaction syndrome}

The inclusion criteria for the diagnosis of ulnar impaction syndrome were:

1) a history of ulnar side wrist pain, aggravated rotation, and ulnar deviation of the wrist during wrist rotation or squeezing objects, or difficulty in holding or lifting objects;

2) positive findings such as tenderness around the ulnar styloid process (the fovea sign), an ulnocarpal stress test, and an ulnocarpal grind test;

3) radiographic finding of ulnar positive variance or neutral variance in the PA wrist view;

4) degenerative findings of triangular fibrocartilage complex (TFCC) in magnetic resonance imaging (MRI).

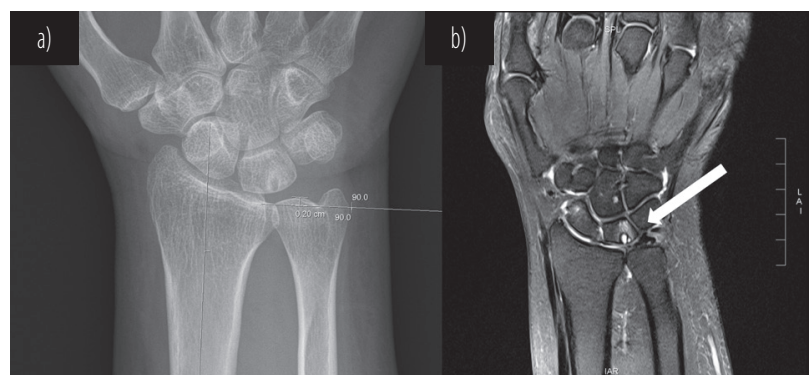

Figure 2. Radiographic findings of ulnar impaction syndrome in fishery workers including oyster shuckers taking part in the analysis, October 2015-August 2017, Gyeongsang National University Hospital, Republic of Korea: a) X-ray, b) magnetic resonance imaging (white arrow: bone marrow edema of lunate bone)

Finally, ulnar impaction syndrome was diagnosed when (1) was always present, and (2), (3) and (4) had occurred at least once [5].

The exclusion criteria were:

- a history of trauma or surgery around the wrist;

- a radiologic finding of advanced OA of the distal radioulnar joint;

- a history of inflammatory arthritis, such as rheumatoid arthritis, gouty arthritis, and infectious arthritis;

- the presence of an abnormality of the carpal bone, such as Kienbock's disease, scaphoid nonunion, or carpal instability (Figure 2).

\section{Evaluation method for exposure to burden work}

Type of fishery (oyster shucking, aquaculture/offshore fishery)

The participants in this study were recruited by classifying them into occupations by oyster shucking in 2015 and aquaculture/offshore fishery in 2016. As a control group in 2017, office workers were recruited and analyzed. During the 3-year recruitment period, subjects from different occupations were enrolled to analyze the differences in the disease prevalence by type of fishery.

\section{Occupation-related burden factors}

Repetitive or improper postures and tasks that exert pressure on the hand have been classified as major risk factors 
for hand or wrist musculoskeletal disorders. For having these risk factors, the authors set the risk to increase when there were additional factors such as shock or vibration. Otherwise, it was judged that the burden level was low.

The 4 factors for occupation-related burden were classified as follows:

- Factor 1 - when the wrist motion is repeated every few seconds or the wrist posture is bad;

- Factor 2 - work that requires continuous force on the finger (fixture: $\geq 0.9 \mathrm{~kg}$ ) or wrist (grip force: $\geq 4.5 \mathrm{~kg}$ );

- Factor 3 - work exposed to local vibration, such as the operation of a mower or a cultivator;

- Factor 4 - work that uses the back of the hand like a hammer ( $>20$ times/day).

\section{Statistical analysis}

In the descriptive analysis, the authors analyzed categorical variables using a $\chi^{2}$ test or Fisher's exact test, and continuous variables by a t-test or 1-way ANOVA.

For the multiple regression analysis, the authors found that factors 1 and 2 were always $>50 \%$, while factors 3 and 4 were often $25-50 \%$, which increased the workload. Repetition/attitude/force (factor $1+$ factor 2) was defined as always $\geq 50 \%$ in factor 1 (repeat/posture), and at the same time always $\geq 50 \%$ in factor 2 (force). Vibration (factor 3) or shock (factor 4) was defined as when either vibration or shock was frequently 25-50\%.

Risk exposure levels were categorized based on repetition/posture/force, and were classified as having a burden level lower than this or having an additional burden level. In addition to this classification, risk exposure levels were classified by calculating the sums of the 4 workload factors. The authors carried out statistical analyses using SPSS for Windows software, v. 22.0 (SPSS, Chicago, IL, USA) and software R, v. 3.1.0 (The R 100 Foundation, Vienna, Austria), with $\mathrm{p}<0.05$ considered significant.

\section{RESULTS}

\section{Baseline characteristics of the participants}

A total of 590 subjects were analyzed. The percentage of females was higher in both oyster shuckers (females: $85.8 \%$ vs. males: $14.2 \%, \mathrm{p}<0.001$ ) and office jobs (females: $66.8 \%$ vs. males: $34.0 \%, \mathrm{p}<0.001)$. In oyster shuckers (aged $\geq 60$ years: $71.1 \%$ vs. $<60$ years: $28.9 \%, p<0.001$ ) and office workers (aged $>60$ years: $59.3 \%$ vs. $<60$ years: $40.7 \%, \mathrm{p}<0.001$ ), the proportion of people aged $>60$ years was high, and the ratio of those aged $<60$ years was high in aquaculture/offshore fishery workers ( $>60$ years: $48.8 \%$ vs. $<60$ years: $51.2 \%, \mathrm{p}<0.001$ ) with high work intensity. For obesity, there were statistically significantly higher rates in oyster shuckers (44.2\%) and aquaculture/offshore fishery workers (40.8\%) than among office workers $(28.0 \%, \mathrm{p}=$ $0.006)$

The percentage of work experience of $>30$ years was statistically significantly higher for office workers $(57.3 \%)$ than for oyster shuckers (37.4\%) and aquaculture/offshore fishery workers $(39.6 \%, \mathrm{p}<0.001)$. The baseline characteristics of the participants are summarized in Table 1.

\section{Occupational burden factors and levels}

Analyzing the exposure of the 4 occupational burden factors, in all factors the frequency of exposure to $>50 \%$ of the burden factors was statistically significantly higher for oyster shuckers than for aquaculture, offshore fishery workers or office workers (Table 2).

In the workload level analysis, the proportion of burden factors, such as work repetition, posture, force, vibration, and shock, was statistically significantly higher for oyster shuckers $(21.1 \%)$ than for aquaculture/offshore fishery workers $(9.2 \%)$ or office workers $(0 \%)(\mathrm{p}<0.001)$ (Table 3$)$.

\section{Prevalence of hand OA, CTS, and ulnar impaction syndrome}

The prevalence of females was significantly higher than that of males in hand OA $(\mathrm{p}<0.001)$, CTS ( $\mathrm{p}=0.003)$, and ulnar 
Table 1. General characteristics of fishery workers including oyster shuckers taking part in the analysis, October 2015-August 2017, Gyeongsang National University Hospital, Republic of Korea

\begin{tabular}{|c|c|c|c|c|c|}
\hline \multirow[b]{2}{*}{ Variable } & \multicolumn{4}{|c|}{$\begin{array}{l}\text { Participants } \\
(\mathrm{N}=590)\end{array}$} & \multirow[b]{2}{*}{$\mathrm{p}$} \\
\hline & $\begin{array}{l}\text { oyster shuckers } \\
\qquad(\mathrm{N}=190)\end{array}$ & $\begin{array}{l}\text { aquaculture/offshore } \\
\text { fishery workers } \\
(\mathrm{N}=250)\end{array}$ & $\begin{array}{l}\text { office workers } \\
\quad(\mathrm{N}=150)\end{array}$ & total & \\
\hline $\operatorname{Sex}[\mathrm{n}(\%)]$ & & & & & $<0.001$ \\
\hline male & $27(14.2)$ & $127(50.8)$ & $51(34.0)$ & $205(34.7)$ & \\
\hline female & $163(85.8)$ & $123(49.2)$ & $99(66.0)$ & $385(65.3)$ & \\
\hline Age $[\mathrm{n}(\%)]$ & & & & & $<0.001$ \\
\hline$<60$ years & $55(28.9)$ & $128(51.2)$ & $61(40.7)$ & $244(41.4)$ & \\
\hline $60-69$ years & $71(37.4)$ & $107(42.8)$ & $60(40.0)$ & $238(40.3)$ & \\
\hline$\geq 70$ years & $64(33.7)$ & $15(6.0)$ & $29(19.3)$ & $108(18.3)$ & \\
\hline Age $(\mathrm{M} \pm \mathrm{SD})$ & $61.8 \pm 8.1$ & $64.9 \pm 9.0$ & $59.5 \pm 6.5$ & $61.9 \pm 8.2$ & \\
\hline Obesity [n (\%)] & & & & & 0.006 \\
\hline normal & $106(55.8)$ & $148(59.2)$ & $108(72.0)$ & $362(61.4)$ & \\
\hline obesity & $84(44.2)$ & $102(40.8)$ & $42(28.0)$ & $228(38.6)$ & \\
\hline Education [n (\%)] & & & & & $<0.001$ \\
\hline elementary school & $151(79.5)$ & $105(42.0)$ & $0(0.0)$ & $256(43.4)$ & \\
\hline middle school & $24(12.6)$ & $81(32.4)$ & $8(5.3)$ & $113(19.2)$ & \\
\hline high school & $15(7.9)$ & $64(25.6)$ & $142(94.7)$ & $221(37.5)$ & \\
\hline Insurance $[\mathrm{n}(\%)]$ & & & & & 0.042 \\
\hline health insurance & $181(95.3)$ & $246(98.4)$ & $150(100.0)$ & $577(97.8)$ & \\
\hline potential poverty & $3(1.6)$ & $1(0.4)$ & $0(0.0)$ & $4(0.7)$ & \\
\hline medical care & $6(3.2)$ & $3(1.2)$ & $0(0.0)$ & $9(1.5)$ & \\
\hline Fishery period* $[\mathrm{n}(\%)]$ & & & & & $<0.001$ \\
\hline$<10$ years & $38(20.0)$ & $37(14.8)$ & $13(8.7)$ & $88(14.9)$ & \\
\hline $10-19$ years & $52(27.4)$ & $39(15.6)$ & $21(14.0)$ & $112(19.0)$ & \\
\hline 20-29 years & $29(15.3)$ & $75(30.0)$ & $30(20.0)$ & $134(22.7)$ & \\
\hline$\geq 30$ years & $71(37.4)$ & 99 (39.6) & $86(57.3)$ & $256(43.4)$ & \\
\hline
\end{tabular}

* The control group (office workers) was defined as performing office work (teachers, public officials).

impaction syndrome $(\mathrm{p}<0.001)$. In addition, the prevalence of $\mathrm{OA}(\mathrm{p}<0.001)$ and ulnar impaction syndrome $(\mathrm{p}<0.001)$ increased to a statistically significant degree with increasing age. Carpal tunnel syndrome was significantly higher in obese patients $(67.1 \%, \mathrm{p}<0.001)$. Hand OA $(\mathrm{p}<0.001)$,
CTS ( $\mathrm{p}<0.001)$, and ulnar impaction syndrome $(\mathrm{p}<0.001)$ showed a higher prevalence among junior high-school graduates or those younger than high-school graduates.

Fishing experience did not show any statistical significance for the 3 diseases. In terms of fishery occupations, however, 
Table 2. The occupational burden factor exposure in fishery workers including oyster shuckers taking part in the analysis, October 2015-August 2017, Gyeongsang National University Hospital, Republic of Korea

\begin{tabular}{|c|c|c|c|c|c|c|c|c|c|}
\hline \multirow{3}{*}{ Factor } & \multicolumn{8}{|c|}{$\begin{array}{l}\text { Participants } \\
(\mathrm{N}=590)\end{array}$} & \multirow{3}{*}{$\mathrm{p}$} \\
\hline & \multicolumn{2}{|c|}{$\begin{array}{l}\text { oyster shuckers } \\
\quad(\mathrm{N}=190)\end{array}$} & \multicolumn{2}{|c|}{$\begin{array}{c}\text { aquaculture/ } \\
\text { offshore fishery } \\
\text { workers } \\
(\mathrm{N}=250)\end{array}$} & \multicolumn{2}{|c|}{$\begin{array}{l}\text { office workers } \\
(\mathrm{N}=150)\end{array}$} & \multicolumn{2}{|c|}{ total } & \\
\hline & $\mathrm{n}$ & $\%$ & $\mathrm{n}$ & $\%$ & $\mathrm{n}$ & $\%$ & $\mathrm{n}$ & $\%$ & \\
\hline $\begin{array}{l}\text { Factor } 1 . \text { When the wrist motion is repeated } \\
\text { every few seconds or the wrist posture is bad }\end{array}$ & & & & & & & & & $<0.001$ \\
\hline almost none & 1 & 0.5 & 11 & 4.4 & 22 & 14.7 & 34 & 5.8 & \\
\hline $\operatorname{rare}(<25 \%)$ & 11 & 5.8 & 33 & 13.2 & 40 & 26.7 & 84 & 14.2 & \\
\hline often $(25-50 \%)$ & 22 & 11.6 & 57 & 22.8 & 34 & 22.7 & 113 & 19.2 & \\
\hline always (>50\%) & 156 & 82.1 & 149 & 59.6 & 54 & 36.0 & 359 & 60.8 & \\
\hline $\begin{array}{l}\text { Factor } 2 \text {. Work that requires continuous force } \\
\text { on the finger (fixture: } \geq 0.9 \mathrm{~kg} \text { ) or wrist } \\
\text { (grip force: } \geq 4.5 \mathrm{~kg} \text { ) }\end{array}$ & & & & & & & & & $<0.001$ \\
\hline almost none & 3 & 1.6 & 16 & 6.4 & 121 & 80.7 & 140 & 23.7 & \\
\hline $\operatorname{rare}(<25 \%)$ & 26 & 13.7 & 39 & 15.6 & 22 & 14.7 & 87 & 14.7 & \\
\hline often $(25-50 \%)$ & 32 & 16.8 & 68 & 27.2 & 5 & 3.3 & 105 & 17.8 & \\
\hline always (>50\%) & 129 & 67.9 & 127 & 50.8 & 2 & 1.3 & 258 & 43.7 & \\
\hline $\begin{array}{l}\text { Factor 3. Work exposed to local vibration such } \\
\text { as the operation of a mower or a cultivator }\end{array}$ & & & & & & & & & $<0.001$ \\
\hline almost none & 177 & 93.2 & 181 & 72.4 & 145 & 96.7 & 503 & 85.3 & \\
\hline $\operatorname{rare}(<25 \%)$ & 8 & 4.2 & 34 & 13.6 & 4 & 2.7 & 46 & 7.8 & \\
\hline often $(25-50 \%)$ & 5 & 2.6 & 14 & 5.6 & 1 & 0.7 & 20 & 3.4 & \\
\hline always (>50\%) & 0 & 0.0 & 21 & 8.4 & 0 & 0.0 & 21 & 3.6 & \\
\hline $\begin{array}{l}\text { Factor } 4 \text {. Work that uses the back of your hand like } \\
\text { a hammer to affect ( }>20 \text { times/day) }\end{array}$ & & & & & & & & & $<0.001$ \\
\hline almost none & 104 & 54.7 & 194 & 77.6 & 142 & 94.7 & 440 & 74.6 & \\
\hline $\operatorname{rare}(<25 \%)$ & 31 & 16.3 & 38 & 15.2 & 8 & 5.3 & 77 & 13.1 & \\
\hline often $(25-50 \%)$ & 29 & 15.3 & 13 & 5.2 & 0 & 0.0 & 42 & 7.1 & \\
\hline always (>50\%) & 26 & 13.7 & 5 & 2 & 0 & 0.0 & 31 & 5.3 & \\
\hline
\end{tabular}

oyster shuckers showed a statistically significantly higher prevalence in the 3 diseases (hand OA: $84.2 \%$; CTS: $71.6 \%$; ulnar impaction syndrome: $41.1 \%$ ) compared to office workers and aquaculture/offshore fishery workers. In addition, the higher the workload and the number, the statistically significantly higher prevalence was observed in all 3 diseases (Table 4). 
Table 3. The work burden level and the number of work burden in fishery workers including oyster shuckers taking part in the analysis, October 2015-August 2017, Gyeongsang National University Hospital, Republic of Korea

\begin{tabular}{|c|c|c|c|c|c|c|c|c|c|}
\hline \multirow{3}{*}{ Variable } & \multicolumn{8}{|c|}{$\begin{array}{c}\text { Participants } \\
(\mathrm{N}=590)\end{array}$} & \multirow{3}{*}{$\mathrm{p}$} \\
\hline & \multicolumn{2}{|c|}{$\begin{array}{l}\text { oyster shuckers } \\
\qquad(\mathrm{N}=190)\end{array}$} & \multicolumn{2}{|c|}{$\begin{array}{c}\text { aquaculture/ } \\
\text { offshore fishery } \\
\text { workers } \\
(\mathrm{N}=250) \\
\end{array}$} & \multicolumn{2}{|c|}{$\begin{array}{l}\text { office workers } \\
\quad(\mathrm{N}=150)\end{array}$} & \multicolumn{2}{|c|}{ total } & \\
\hline & $\mathrm{n}$ & $\%$ & $\mathrm{n}$ & $\%$ & $\mathrm{n}$ & $\%$ & $\mathrm{n}$ & $\%$ & \\
\hline \multicolumn{10}{|l|}{ Work burden level } \\
\hline low & 63 & 33.2 & 143 & 57.2 & 149 & 99.3 & 355 & 60.2 & $<0.001$ \\
\hline repetition/posture/power & 87 & 45.8 & 84 & 33.6 & 1 & 0.7 & 172 & 29.2 & \\
\hline repetition/posture/power + vibration/impact & 40 & 21.1 & 23 & 9.2 & 0 & 0.0 & 63 & 10.7 & \\
\hline \multicolumn{10}{|l|}{ Work burden number } \\
\hline low & 28 & 14.7 & 73 & 29.2 & 94 & 62.7 & 195 & 33.1 & $<0.001$ \\
\hline 1 kind & 24 & 12.6 & 58 & 23.2 & 55 & 36.7 & 137 & 23.2 & \\
\hline 2 kinds & 97 & 51.1 & 93 & 37.2 & 1 & 0.7 & 191 & 32.4 & \\
\hline 3-4 kinds & 41 & 21.6 & 26 & 10.4 & 0 & 0.0 & 67 & 11.4 & \\
\hline
\end{tabular}

Table 4. Prevalence of upper limb disease by major factors in fishery workers including oyster shuckers taking part in the analysis, October 2015-August 2017, Gyeongsang National University Hospital, Republic of Korea

\begin{tabular}{|c|c|c|c|c|c|c|c|}
\hline \multirow{3}{*}{ Variable } & \multicolumn{7}{|c|}{$\begin{array}{l}\text { Participants } \\
(\mathrm{N}=590)\end{array}$} \\
\hline & \multirow[t]{2}{*}{ total } & \multicolumn{2}{|c|}{$\begin{array}{c}\text { with hand OA } \\
(\mathrm{N}=448,75.9 \%)\end{array}$} & \multicolumn{2}{|c|}{$\begin{array}{c}\text { with CTS } \\
(\mathrm{N}=340,57.6 \%)\end{array}$} & \multicolumn{2}{|c|}{$\begin{array}{c}\text { with ulnar impaction } \\
\text { syndrome } \\
(\mathrm{N}=96,16.3 \%)\end{array}$} \\
\hline & & $\mathrm{n}$ & $\%$ & $\mathrm{n}$ & $\%$ & $\mathrm{n}$ & $\%$ \\
\hline \multicolumn{8}{|l|}{$\overline{\text { Sex }}$} \\
\hline male & 205 & 129 & 62.9 & 101 & 49.3 & 13 & 6.3 \\
\hline female & 385 & 319 & 82.9 & 239 & 62.1 & 83 & 21.6 \\
\hline \multicolumn{8}{|l|}{ Age } \\
\hline$<60$ years & 224 & 160 & 71.4 & 132 & 58.9 & 23 & 10.3 \\
\hline 60-69 years & 238 & 187 & 78.6 & 148 & 62.2 & 38 & 16.0 \\
\hline$\geq 70$ years & 108 & 101 & 93.5 & 60 & 55.6 & 35 & 32.4 \\
\hline \multicolumn{8}{|l|}{ Obesity } \\
\hline normal & 362 & 282 & 77.9 & 187 & 51.7 & 59 & 16.3 \\
\hline obesity & 228 & 166 & 72.8 & 153 & 67.1 & 37 & 16.2 \\
\hline \multicolumn{8}{|l|}{ Education } \\
\hline elementary school & 256 & 221 & 86.3 & 182 & 71.1 & 73 & 28.5 \\
\hline middle school & 113 & 79 & 69.9 & 72 & 63.7 & 7 & 6.2 \\
\hline high school & 221 & 148 & 67.0 & 86 & 38.9 & 16 & 7.2 \\
\hline
\end{tabular}


Table 4. Prevalence of upper limb disease by major factors in fishery workers including oyster shuckers taking part in the analysis, October 2015-August 2017, Gyeongsang National University Hospital, Republic of Korea - cont.

\begin{tabular}{|c|c|c|c|c|c|c|c|}
\hline \multirow{3}{*}{ Variable } & \multicolumn{7}{|c|}{$\begin{array}{l}\text { Participants } \\
(\mathrm{N}=590)\end{array}$} \\
\hline & \multirow[t]{2}{*}{ total } & \multicolumn{2}{|c|}{$\begin{array}{c}\text { with hand OA } \\
(\mathrm{N}=448,75.9 \%)\end{array}$} & \multicolumn{2}{|c|}{$\begin{array}{c}\text { with CTS } \\
(\mathrm{N}=340,57.6 \%)\end{array}$} & \multicolumn{2}{|c|}{$\begin{array}{c}\text { with ulnar impaction } \\
\text { syndrome } \\
(\mathrm{N}=96,16.3 \%)\end{array}$} \\
\hline & & $\mathrm{n}$ & $\%$ & $\mathrm{n}$ & $\%$ & $\mathrm{n}$ & $\%$ \\
\hline \multicolumn{8}{|l|}{ Insurance } \\
\hline health insurance & 577 & 441 & 76.4 & 333 & 57.7 & 95 & 16.5 \\
\hline potential poverty & 4 & 1 & 25.0 & 2 & 50.0 & 0 & 0.0 \\
\hline medical care & 9 & 6 & 66.7 & 5 & 55.6 & 1 & 11.1 \\
\hline \multicolumn{8}{|l|}{ Fishery period } \\
\hline$<10$ years & 88 & 67 & 76.1 & 53 & 60.2 & 15 & 17.0 \\
\hline 10-19 years & 112 & 84 & 75.0 & 66 & 58.9 & 28 & 25.0 \\
\hline 20-29 years & 134 & 98 & 73.1 & 79 & 59.0 & 10 & 7.5 \\
\hline$\geq 30$ years & 256 & 199 & 77.7 & 142 & 55.5 & 43 & 16.8 \\
\hline \multicolumn{8}{|l|}{ Occupation (survey year) } \\
\hline office worker (2017) & 150 & 113 & 75.3 & 38 & 25.3 & 13 & 8.7 \\
\hline aquaculture/offshore fishery worker (2016) & 250 & 175 & 70.0 & 166 & 66.4 & 5 & 2.0 \\
\hline oyster shucker (2015) & 190 & 160 & 84.2 & 136 & 71.6 & 78 & 41.1 \\
\hline \multicolumn{8}{|l|}{ Work burden level } \\
\hline low & 355 & 255 & 71.8 & 164 & 46.2 & 46 & 13.0 \\
\hline repetition/posture/power & 172 & 137 & 79.7 & 125 & 72.7 & 33 & 19.2 \\
\hline repetition/posture/power + vibration/impact & 63 & 56 & 88.9 & 51 & 81.0 & 17 & 27.0 \\
\hline \multicolumn{8}{|l|}{ Work burden number } \\
\hline low & 195 & 146 & 74.9 & 83 & 42.6 & 19 & 9.7 \\
\hline 1 kind & 137 & 94 & 68.6 & 65 & 47.4 & 18 & 13.1 \\
\hline 2 kinds & 191 & 148 & 77.5 & 139 & 72.8 & 42 & 22.0 \\
\hline 3-4 kinds & 67 & 60 & 89.6 & 53 & 79.1 & 18 & 26.9 \\
\hline
\end{tabular}

CTS - carpal tunnel syndrome; OA - osteoarthritis.

\section{Multivariate logistic regression analysis}

of the relationship between the occupational

burden factor, exposure levels

and upper extremity musculoskeletal disorders

Hand $\mathrm{OA}$

Gender and age were statistically significant risk factors in all 3 models $(p<0.05)$ However, the duration of fishing was not statistically significant. The occupational burden level was significantly related in model $1(\mathrm{p}<0.05)$, and the number of occupational burdens was significant in model 2 ( $p<0.05)$. However, no statistical significance was observed according to occupation (Table 5).

CTS

Age was not statistically significant in any of the 3 models. However, all the 3 models $(\mathrm{p}<0.05)$ showed a statistically 


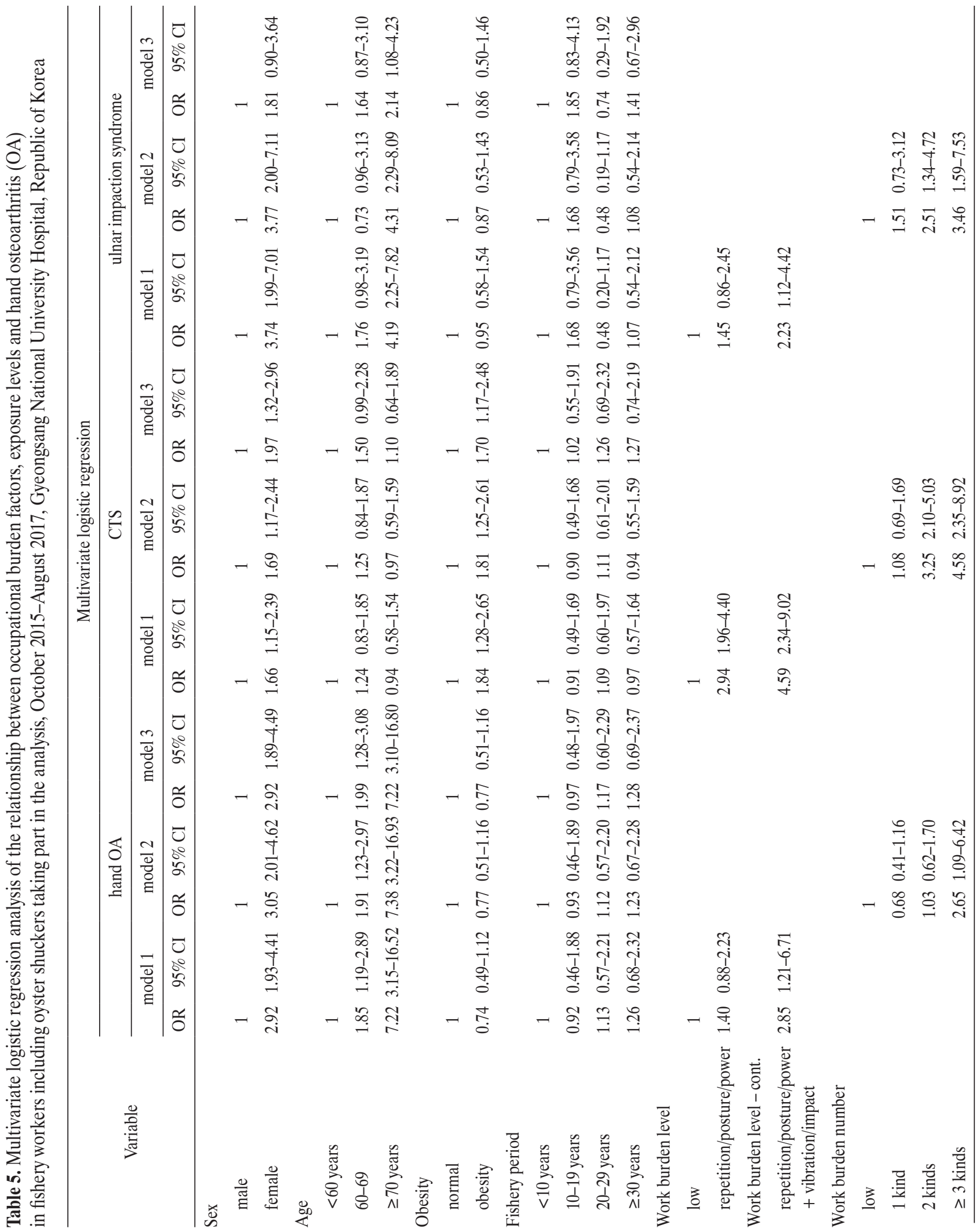




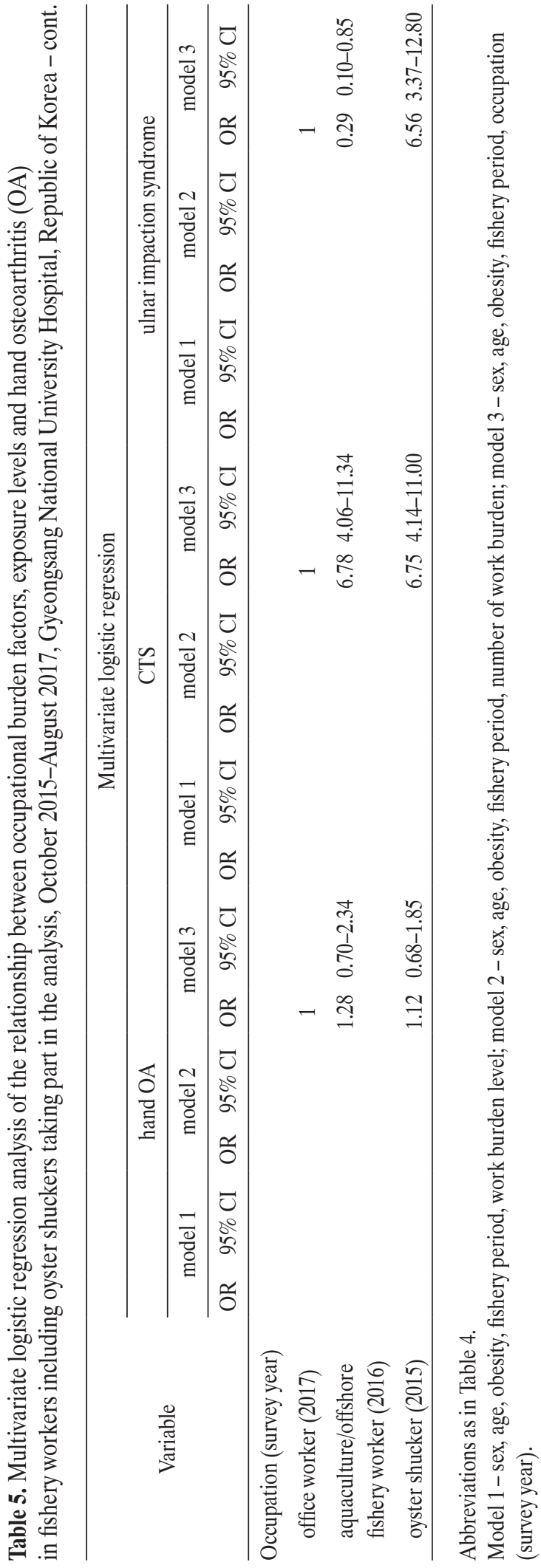

significant high prevalence both for women and obesity. The duration of fishing was not statistically significant.

The occupational burden level was significant in model 1 $(\mathrm{p}<0.05)$, and the number of job burdens was significantly related in model $2(\mathrm{p}<0.05)$. No statistical significance was observed according to occupation.

\section{Ulnar impaction syndrome}

There were no statistically significant differences in sex and age in all the 3 models, and the duration of fishing was not statistically significant. The occupational burden level was significant in model $1(\mathrm{p}<0.05)$, and the number of job burdens was significantly related in model $2(\mathrm{p}<0.05)$.

Oyster shuckers had a higher risk of ulnar impaction syndrome than did office workers. However, the risk of ulnar impaction syndrome was lower in aquaculture/offshore fishery workers than in office workers.

\section{DISCUSSION}

The main findings of this study were that the prevalence of hand OA, CTS, and ulnar impaction syndrome was higher in oyster strippers than in aquaculture/offshore fishery workers. In oyster shuckers, the prevalence of hand OA was $84 \%$, that of CTS was $72 \%$, and that of ulnar impaction syndrome was $41 \%$. The prevalence of upper limb disease was higher in oyster shuckers than in other fishery workers, even in the prevalence of exposure to occupational burden factors.

\section{Baseline characteristics of the participants (sex and age)}

All fishers as well as office workers had a high prevalence of hand OA, probably because of the high average age of the subjects included in the study. In addition, unlike other regions, because of the aging of the population and the lack of work force, Gyeongsangnam-do has a high age rate and fisheries experience. For this reason, the incidence of work-related hand diseases seems to result from the burden of fishing work. 
Previous studies have reported that being older is the most important risk factor of hand OA among women [6]. The study group also had a large proportion of the elderly and women, and both the risk and prevalence of hand OA were high.

\section{Occupational burden factors and exposure levels}

According to the existing epidemiological studies, the risk factor alone does not significantly increase the risk of musculoskeletal disorders, but the risk increases when $\geq 2$ factors are present at the same time [7]. In addition, it was difficult to assess the effect of individual risk factors, because the distribution of the burden factors tended to be biased to one side among the subjects included in this study. In this study, therefore, the most basic hand-bearing task, a repetitive or improper posture, while simultaneously applying power, was classified as a basic risk factor for wrist and hand musculoskeletal disorders.

In this study, the movement of the hand during oyster shucker's work, a "dart throw motion" [8], occurred repeatedly in the hands holding the knife with ulnar deviation + volar flexion and radial deviation + dorsiflexion. On the other hand, the non-working hand holding the oyster experienced repeated flexion and extension of the wrist while holding the oyster (Figure 3).

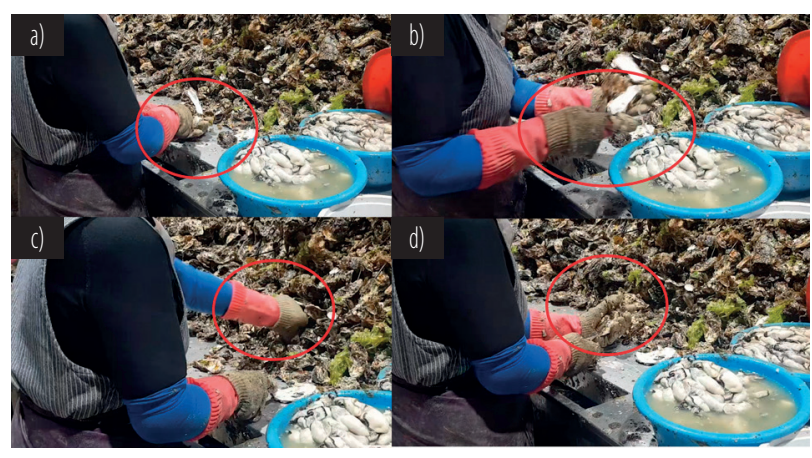

Figure 3. The movement of the hand during oyster shucker's work, a "dart throw motion" occurred repeatedly in the hands holding the knife with a) ulnar deviation + volar flexion and b) radial deviation + dorsiflexion. On the other hand, the non-working hand holding the oyster experienced repeated c) flexion and d) extension of the wrist while holding the oyster
Theoretically, the hand where the knife operation is done may increase loading on the scaphotrapeziotrapezoid joint around the TFCC and the scaphoid, and may be vulnerable to OA occurrence while the knife is grasped and loaded on both thumb basal joints [9]. In addition, since the hand holding the oyster needs to hold it for a long time and maintain the bending position of the wrist, the risk of developing a hand disease is expected to increase as loading is applied to the pisohamate joint and TFCC, which are flexor carpi ularis insertions.

\section{Prevalence of hand OA, CTS, and ulnocarpal impaction syndrome Hand $\mathrm{OA}$}

Similar to other epidemiology studies for hand or wrist OA, gender and age were the major risk factors [6,10]. However, in this study, the age increase in the occupation of oyster shuckers was not a risk factor for hand OA, probably because arthritis is a degenerative disease of the hand that progresses gradually over a long period of time, and the average age of the study subjects was $\geq 60$ years. In this study, the prevalence of hand OA was $75.9 \%$, most of which would have been advanced. As the population density in cities is accelerating, often only the elderly population remains in the fishing area. Therefore, in the future, hand OA will be an important health concern for oyster shuckers, with there being more and more elderly female workers.

Because the wrist and the hand are joints not related to weight load, obesity was not a risk factor. In addition, the risk of increasing the burden of complex exposure was caused by the workload factor. However, there was no statistically significant difference between the fishery period and the type of occupation.

CTS

Incidence rates of $\leq 276 / 100000$ population per year have been reported, with a prevalence rate of $\leq 9.2 \%$ in 
women and $6 \%$ in men [11]. In the present study, CTS was not related to age. However, as in previous epidemiological studies, the prevalence of CTS was higher for both women and obesity. In addition, it showed a very clear relationship with the workload, but the duration of fishing was not related.

\section{Ulnar impaction syndrome}

Ulnar impaction syndrome is a disease affecting the wrist joints, such as hand arthritis, which can be caused by a positive variation of the ulna or external factors such as the posture of ulnar deviation [12]. In this study, gender and age were clearly related, and obesity was not significantly related. Moreover, the duration of the fishery period was not relevant.

The burden of work was relatively clearly related. The typical pain-generating movements in patients with ulnar impaction syndrome are movements in everyday life, such as turning the bottle cap, opening the door, squeezing the mop, or turning a gas range [13]. In the present study, oyster shuckers had a higher risk of ulnar impaction syndrome than did white-collar workers, but for aquaculture/ offshore fishery workers, the risk of ulnocarpal impaction syndrome was lower than that for white-collar workers, probably because of the difference in the posture of ulnar deviation according to occupation.

There were several limitations of this study. First, it used a cross-sectional study design. During the 3-year recruitment period, selection bias could have occurred in the study by recruiting subjects from different occupations. Second, the evaluation of the workload was conducted through a questionnaire.

Nevertheless, this study examined the prevalence of hand and wrist diseases diagnosed through objective examinations, such as MRI, X-ray and electromyography, for oyster shuckers and other fishery occupations, and objectively proved that the burden on the hands of oyster shuckers was high.

\section{CONCLUSIONS}

In oyster shuckers, the incidence of hand and wrist OA was $84 \%$, that of CTS was $72 \%$, and that of ulnar impaction syndrome was $41 \%$. In addition, oyster shuckers were more likely to be exposed to occupational burden factors than were other types of fishermen. Therefore, the authors think that proper stretching or exercise for rest and musculoskeletal relaxation, as well as health-care education and promotion, will be needed for the fishermen's repeated posture and impact work.

\section{REFERENCES}

1. Choi K-S. Oyster capture-based aquaculture in the Republic of Korea. In: Lovatelli A, Holthus PF, editors. Capture-based aquaculture. Global overview. Rome: Fisheries Tech Paper; 2008. p. 271-86.

2. Hsu DJ, Chang JH, Wu JD, Chen CY, Yang YH. Prevalence of musculoskeletal disorders and job exposure in Taiwan oyster shuckers. Am J Ind Med. 2011;54(11):885-93, https://doi. org/10.1002/ajim.20976.

3. Altman R, Alarcón G, Appelrouth D, Bloch D, Borenstein D, Brandt K, et al. The American College of Rheumatology criteria for the classification and reporting of osteoarthritis of the hand. Arthritis Rheum. 1990;33(11):1601-10, https://doi. org/10.1002/art.1780331101.

4. Keith MW, Masear V, Chung K, Maupin K, Andary M, Amadio PC, et al. Diagnosis of Carpal Tunnel Syndrome. J Am Acad Orthop Surg. 2009;17(6):389-96, https://doi.org/10.5435/ 00124635-200906000-00007.

5. Sammer DM, Rizzo M. Ulnar impaction. Hand Clin. 2010; 26(4):549-57, https://doi.org/10.1016/j.hcl.2010.05.011.

6. Kalichman L, Hernández-Molina G. Hand osteoarthritis: an epidemiological perspective. Semin Arthritis Rheum. 2010;39(6):465-76, https://doi.org/10.1016/j.semarthrit.2009. 03.001.

7. Gallagher S, Heberger JR. Examining the Interaction of Force and Repetition on Musculoskeletal Disorder Risk: A Systematic Literature Review. Hum Factors. 2013;55(1):108-24. 
8. Garcia-Elias M, Serrallach XA, Serra JM. Dart-throwing motion in patients with scapholunate instability: a dynamic four-dimensional computed tomography study: J Hand Surg. 2014;39(4), https://doi.org/10.1177/1753193413484630.

9. Casadei K, Kiel J. Triangular Fibrocartilage Complex (TFCC) Injuries. StatPearls. Treasure Island, FL: StatPearls Publishing; 2020 [cited 2020 May 4]. Available from: http:// www.ncbi.nlm.nih.gov/books/NBK537055/.

10. Marshall M, Watt FE, Vincent TL, Dziedzic K. Hand osteoarthritis: clinical phenotypes, molecular mechanisms and disease management. Nature Rev Rheumatol. 2018;14(11):64156, https://doi.org/10.1038/s41584-018-0095-4.
11. Mondelli M, Giannini F, Giacchi M. Carpal tunnel syndrome incidence in a general population. Neurology. 2002 22;58(2):289-94, https://doi.org/10.1212/wnl.58.2.289.

12. Sammer DM, Rizzo M. Ulnar impaction. Hand Clin. 2010;26(4):549-57, https://doi.org/10.1016/j.hcl.2010.05.011.

13. Kim J, Gong HS, Baek GH. Updates on Ulnar Impaction Syndrome. J Korean Orthop Assoc. 2017;52(2):103, https:// doi.org/10.4055/jkoa.2017.52.2.103.

This work is available in Open Access model and licensed under a Creative Commons Attribution-NonCommercial 3.0 Poland License - http://creativecommons.org/ licenses/by-nc/3.0/pl/deed.en. 